\title{
Associations between matrix metalloproteinase, tissue inhibitor of metalloproteinase and collagen expression levels in the adjacent rectal tissue of colorectal carcinoma patients
}

\author{
KATARINA DIBDIAKOVA ${ }^{1}$, ADAM SVEC ${ }^{2}$, ZUZANA MAJERCIKOVA ${ }^{1}$, MAREK ADAMIK ${ }^{2}$, \\ MARIAN GRENDAR ${ }^{3}$, JURAJ VANA ${ }^{4}$, ALEXANDER FERKO ${ }^{2}$ and JOZEF HATOK ${ }^{1}$ \\ Departments of ${ }^{1}$ Medical Biochemistry and ${ }^{2}$ Surgery and Transplant Centre, ${ }^{3}$ Biomedical Center Martin, \\ Jessenius Faculty of Medicine in Martin, Comenius University in Bratislava, SK-03601 Martin; \\ ${ }^{4}$ Department of Surgery, The Faculty Hospital, SK-01207 Zilina, Slovakia
}

Received March 17, 2021; Accepted August 23, 2021

DOI: $10.3892 / \mathrm{mco} .2021 .2475$

\begin{abstract}
As the commonest type of cancer in Europe and the third most common type of cancer worldwide, colorectal carcinoma (CRC) poses a challenge for numerous scientific studies. At present, the cause of this disease is remains to be elucidated, but early diagnosis is only one solution to prevent serious health complications. As a structural scaffold, the extracellular matrix (ECM) is in direct contact with tumour cells and significantly interferes with tumour progression. During the process of tumorigenesis, the ECM undergoes structural changes in which collagens serve an important role. Their life cycle is regulated by proteolytic enzymes called matrix metalloproteinases (MMPs), which are controlled by tissue inhibitors of metalloproteinases (TIMPs). The present study analysed the gene expression of MMPs (MMP1-2-8-10-13), TIMPs (TIMP1-2-4) and collagens (COL1A1 and COL3AI) and the correlation with biochemical parameters in the adjacent rectal tissue (ART) of patients with CRC. The patients who underwent standard neoadjuvant pre-therapy showed increased concentrations of collagen in the normal ART. The mRNA levels of COL3A1, TIMP1 and TIMP2 were significantly higher in the ART of CRC patients (with or without pre-therapy) when compared with the control group. This finding suggested that TIMPs served an important role in the regulation of MMPs and in the modification of collagen content in the ECM. Despite the small data set, the present study provided insights into the
\end{abstract}

Correspondence to: Dr Jozef Hatok, Department of Medical Biochemistry, Jessenius Faculty of Medicine in Martin, Comenius University in Bratislava, Mala Hora 11161/4D, SK-03601 Martin, Slovakia

E-mail: hatok@jfmed.uniba.sk

Key words: colorectal carcinoma, adjacent tissue, metalloproteinase, collagen transcriptomic relationships between the individual genes that are an integral part of the ECM.

\section{Introduction}

Colorectal carcinoma (CRC), a malignant tumour of the colon and rectum, is one of the commonest types of cancer in economically developed countries (1). The number of newly diagnosed cases of cancer is growing worldwide each year (19.3 million in 2020) and it is expected that it will continue to increase as the human population grows and ages (2). CRC is the third commonest type of cancer worldwide and poses a significant health risk to the population (1). In $\sim 50 \%$ of the cases of CRC, the initial phase of therapy is successful, but the long-term survival of the patients is influenced by metastases formation (3), especially in higher $\mathrm{T}$ stages. Resection of the primary tumour is essential for radical treatment for a chance of long-term survival. Rectal resection for cancer is still associated with considerable morbidity. Acute leak (AL) is probably the most serious complication, which is associated with increased postoperative mortality, long-term consequences and negative impact on function (4) and oncological outcomes (5-7). A large proportion of patients with AL (20\%) end up with an unplanned definitive stoma (8) and increased economic costs associated with treatment for complications and a prolonged stay at the Intensive Care Unit should be taken into account $(9,10)$. Several papers analysing preoperative, intraoperative and postoperative factors associated with the development of AL have been published (11-13). It can be said that being male, neoadjuvant radiotherapy and low localisation of anastomosis are generally accepted risk factors for $\mathrm{AL}$ development (14).

The stability of the extracellular matrix (ECM) serves a pivotal role in colon cancer progression. One important factor that regulates cancer-related events at different tumorigenesis stages is the presence of collagens, which are the main components of this three-dimensional network (15). As the most abundant proteins, collagens mainly serve structural roles and contribute to mechanical properties, organisation and the shape of tissues (15). Today, the 28 known collagen (COL) 
types are classified into four subfamilies on the basis of their supramolecular assemblies (16). COLI, COLIII and COLV are mainly produced by fibroblasts, while COLIV is predominantly expressed by epithelial and endothelial cells $(17,18)$. In healthy tissue, the ECM is constantly undergoing remodelling to maintain tissue integrity and function and new collagens are synthesised to replace old collagens destined for degradation (19). During the process of tumorigenesis, the ECM undergoes structural changes (19). The content and distribution of collagen is modified to further coordinate the biological properties of cancer cells, including various gene mutations, transcription factors, signal transduction pathways and receptors (20). The balance between collagen formation and degradation is closely monitored by proteolytic enzymes called matrix metalloproteinases (MMPs). The eight structural classes of MMPs involve a family of zinc-dependent endopeptidases that consist of $>21$ human MMPs and numerous homologues from other species. These enzymes participate in tissue remodelling under physiological and pathological conditions by degradation of major protein components of the ECM and basement membranes. MMPs are upregulated in almost every type of human cancer and can promote cancer progression by increasing cancer cell growth, migration, invasion, metastasis and angiogenesis $(21,22)$.

The functions of MMPs are controlled by endogenous tissue-specific inhibitors and secreted proteins, called tissue inhibitors of metalloproteinases (23). By binding to enzymatically active MMPs, tissue inhibitors of metalloproteinases (TIMPs) inhibit their proteolytic activity, which is essential for the homeostasis of the ECM (24). It could be hypothesized that MMPs and TIMPs may not only serve an important role in tumour invasion and metastasis but also in carcinogenesis. Previous studies have demonstrated that high preoperative serum or plasma MMP-2, MMP-9 and TIMP-1 antigen levels are strong predictive factors for poor prognosis in patients with carcinoma (25) and their determination and identification might be useful for patients with a higher risk for cancer recurrence (26).

The objective of the present study was to analyse the gene expression of MMPs (MMP1-2-8-10-13), TIMPs (TIMP1-2-4) and collagen (COL1A1 and COL $3 A 1)$ and their correlation with biochemistry variables in rectal tissue after surgical resection of rectal adenocarcinoma.

\section{Materials and methods}

Patients and tissue specimens. All analysed samples (Table I) were obtained from consecutive patients who underwent a laparoscopic low anterior resection with total mesorectal excision for rectal adenocarcinoma. The anastomosis was constructed by the double stapling method (27). Preoperative staging was performed by either computed tomography or magnetic resonance imaging of the abdomen and the pelvis. Patients with locally advanced tumours, T3 tumours and T4 tumours with or without involvement of the lymph nodes received preoperative full course chemoradiotherapy (CHRT) to downstage the tumour.

If patients had undergone CHRT, restaging was performed within 6 weeks of CHRT completion and surgery was performed 10 weeks after CHRT completion. The standard
CHRT regimen involved irradiation with 45 Gy in 25 fractions to the pelvic area, the rectum and the pararectal, presacral and internal iliac lymph nodes. A supplementary boost dose of radiation was applied to the tumour itself (5.4 Gy in 3 fractions) for a total dose of $50.4 \mathrm{~Gy}$. Radiotherapy was potentiated by chemotherapy with continuous 5 -fluorouracil infusion at a dose of $200 \mathrm{mg} / \mathrm{m}^{2} / 24 \mathrm{~h}$ for the entire duration of radiotherapy.

Surgical procedures took place in the between March 2019 and December 2020 at two medical institutions: The University Hospital Martin and Faculty Hospital with an outpatient clinic in Zilina. After terminating the resection phase of the surgical procedure, two small samples of the intestinal wall (normal adjacent tissue) were cut from the specimen by an operating surgeon. Adjacent rectal tissues (ARTs) were obtained $10.0-15.00 \mathrm{~cm}$ away from the primary tumour and immediately frozen and stored at $-80^{\circ} \mathrm{C}$ for quantitative polymerase chain reaction (qPCR) and estimation of hydroxyproline. The total number recruited for the present study (adjacent rectal tissues of patients with rectal adenocarcinoma) was 29, of which 12 were without therapy and 17 with neo-adjuvant therapy. The present study was performed according to the Guidelines of the World Medical Association Declaration of Helsinki. The Ethics committee of Jessenius Faculty of Medicine CU in Martin with certification code no. IRB00005636 approved the study and written informed consent was given by all patients.

Collagen concentration in rectal tissue of patients. Hydroxyproline, a major component of collagen, was quantified as a measure of the collagen content using the Total collagen Colorimetric Assay kit (BioVision, Inc.). The assay is based on the acid hydrolysis of samples to form hydroxyproline. Adjacent rectal samples were homogenized in $\mathrm{dH}_{2} \mathrm{O}$, using $100 \mu \mathrm{l} \mathrm{H}_{2} \mathrm{O}$ for every $10 \mathrm{mg}$ of tissue (a of total $80 \mathrm{mg}$ of tissue was used).

To a $100 \mu \mathrm{l}$ sample of homogenate, $100 \mu \mathrm{l}$ of concentrated $\mathrm{HCl}(\sim 12 \mathrm{M})$ was added in a pressure-tight, Teflon-capped vial and hydrolysed at $120^{\circ} \mathrm{C}$ for $3 \mathrm{~h}$. A total of $10 \mu \mathrm{l}$ of each hydrolysed sample was transferred to a 96-well plate and evaporated to dryness under a vacuum. A total of $100 \mu \mathrm{l}$ of the chloramine $\mathrm{T}$ reagent was added to each sample and standard and incubated at room temperature for $5 \mathrm{~min}$. Then, $100 \mu \mathrm{l}$ of the $\mathrm{p}$-dimethylaminobenzaldehyde (DMAB) reagent was added to each well and incubated for $90 \mathrm{~min}$ at $60^{\circ} \mathrm{C}$. Finally, absorbance at $560 \mathrm{~nm}$ was measured by Synergy HTX Multi-Mode Microplate Reader (BioTek Instruments, Inc.). The collagen concentration was expressed in total amount of collagen $\mu \mathrm{g}$ to mg dry tissue.

RNA extraction and reverse transcription quantitative $R T$ - $q P C R$. Colorectal tissue samples stored frozen at $-80^{\circ} \mathrm{C}$ in stabilizing reagent (RNAlater; Qiagen, Inc.) were used for total RNA isolation. The samples $\sim 25 \mathrm{mg}$ were disrupted in QIAZOL Lysis reagent (Qiagen, Inc.) by Polytron PT 1600 E homogeniser (Kinematica AG). The RNA was isolated by using RNeasy Plus Universal kit (Qiagen, Inc.) and measured by spectrometry using a Implen P300 NanoPhotometer (Implen GmbH). A total of $2 \mu \mathrm{g}$ of purified cellular RNA was converted to single stranded cDNA using $\mathrm{RT}^{2}$ First Strand kit (Qiagen, Inc.) according to protocol supplied by the manufacturer. The newly synthesized and diluted cDNA was used for studying multigene 
Table I. Patient characteristics.

\begin{tabular}{lcc}
\hline Variable & [ART-] & 12 \\
\hline Number of patients & & $17+]$ \\
Age & $45-77$ & $35-70$ \\
Range & $60 \pm 11$ & $57 \pm 11$ \\
Mean \pm SEM & & 4 \\
Sex & 7 & 13 \\
Female & $27 \pm 5$ & $26 \pm 4$ \\
Male & & $40 \pm 4(\mathrm{~g} / \mathrm{l})$ \\
BMI (mean \pm SEM) & $39 \pm 6(\mathrm{~g} / \mathrm{l})$ \\
Proteins in plasma (mean \pm SEM) & $5 \pm 3(\mathrm{mg} / \mathrm{l})$ & $4 \pm 3(\mathrm{mg} / \mathrm{l})$ \\
Albumin & $65 \pm 9(\mathrm{~g} / \mathrm{l})$ & $71 \pm 6(\mathrm{~g} / \mathrm{l})$ \\
CRP & $8 \times 10^{9} / 1$ & $6.4 \times 10^{9} / 1$ \\
Total & $119 \pm 67(\mu \mathrm{g} / \mathrm{mg})$ & $17482(\mu \mathrm{g} / \mathrm{mg})$ \\
Leukocytes (mean) & $13 \pm 5(\mu \mathrm{mol} / \mathrm{l})$ & $16 \pm 9(\mu \mathrm{mol} / \mathrm{l})$ \\
Collagen (mean \pm SEM) & & \\
Plasma iron (mean \pm SEM) & & \\
\hline
\end{tabular}

Adjacent rectal tissues (ART) were obtained 10.0-15.00 cm away from the primary tumour. Patients were divided into two groups; patients undergoing neoadjuvant pre-therapy [ART+] and patients without pre-therapy [ART-]. BMI, body mass index; CRP, C-reactive protein.

expression MMPs, tissue inhibitors of MMPs and collagens using the $\mathrm{RT}^{2}$ Profiler PCR Array (Qiagen, Inc.). Three endogenous control genes; glyceraldehyde-3-phosphate dehydrogenase $(G A P D H), \beta$-actin $(A C T B)$ and $\beta 2$-microglobulin $(B 2 M)$ present on the PCR array were used for normalization. The set of primers for all human genes were acquired from $\mathrm{RT}^{2}$ qPCR Primer Assays database (https://geneglobe.qiagen. com/sk/product-groups/rt2-qpcr-primer-assays; Table II).

A reaction mixture prepared according to manufacturer's protocol containing cDNA template $(800 \mathrm{ng})$ and particular volume $(1,240 \mu \mathrm{l})$ of SYBR Green ROX qPCR Mastermix (Qiagen, Inc.) was immediately loaded into each well of 96-well plate of RT $^{2}$ Profiler PCR Array. Each plate was sealed and centrifuged for $1 \mathrm{~min}$ at $1,000 \mathrm{x} \mathrm{g}$ at room temperature and loaded into the ViiA 7 Real-Time PCR System (Thermo Fisher Scientific, Inc.). Amplification of cDNA was initiated by denaturation at $95^{\circ} \mathrm{C}$ for $10 \mathrm{~min}$ followed by 40 PCR stage $\left(95^{\circ} \mathrm{C}, 15 \mathrm{~min} ; 60^{\circ} \mathrm{C}, 1 \mathrm{~min}\right)$ and melting curve stage $\left(95^{\circ} \mathrm{C}\right.$, $\left.15 \mathrm{~min} ; 60^{\circ} \mathrm{C}, 1 \mathrm{~min} ; 95^{\circ} \mathrm{C}, 15 \mathrm{~min}\right)$. The relative changes in gene expression were analysed by using the $2^{-\Delta \Delta \mathrm{Cq}}$ method (28), where $\Delta \Delta \mathrm{Ct}=\left(\mathrm{Ct}_{\mathrm{GOI}}-\mathrm{Ct}_{\mathrm{HKG}}\right)_{\mathrm{TESTING} \text { GROUP }}-\left(\mathrm{Ct}_{\mathrm{GOI}}-\mathrm{Ct}_{\mathrm{HKG}}\right)$ CONTROL GROUP. Commercially available total RNAs from normal rectum tissue were used as a control group for quantitative PCR (Ambsbio; R1234206-50_Human Adult Normal Rectum Tissue and HR-312_Normal Human Rectum Tissue).

Statistical analysis. The relative mRNA levels of ART (both with/without pre-therapy) were compared with normal rectal mRNA by the Welch's ANOVA and Tukey's HSD post hoc test. Relations between gene expression and clinicobiochemical parameters were modelled by multivariate linear regression with all continuous predictors, except for age, and were log-transformed to bring the distributions closer to a Gaussian one. The Akaike Information Criterion was used to reduce the full regression model. The correlation between the log-transformed gene expressions was assessed by the Pearson correlation coefficient. The data were analysed in $\mathrm{R}$ (R Development Core Team, R: A Language and environment for statistical computing, R Foundation for Statistical Computing, Vienna, Austria, URL http://www.R-project.org, 2006). Data are represented as means \pm standard error of mean. All statistical comparisons were performed two-sided in the sense of an exploratory data analysis using ${ }^{*} \mathrm{P}<0.05$, ${ }^{* *} \mathrm{P}<0.01$ and ${ }^{* * *} \mathrm{P}<0.001$ as levels of significance.

Gene expression and fold-change calculations were performed using RT2 Profiler PCR Arrays \& Assays Data Analysis Webportal (https://geneglobe.qiagen.com/us/analyze, Qiagen, Inc.). The genes with a significant difference in expression were those with an average fold-change of $\leq-2.0$ or $\geq 2.0$. $\mathrm{P}<0.05$ was considered to indicate a statistically significant difference.

\section{Results}

Absolute level of $m R N A$ and correlation with clinical data. The absolute pattern of relevant MMPs, TIMPs and COLs was analysed through mRNA expression (Fig. 1). When comparing the absolute levels of gene expression, we decided to represent them in $\log (10)$ of $2^{-\Delta \Delta \mathrm{Cq}}$ values. It should be added that the average $\mathrm{Ct}$ of the control genes (ACTB, GAPDH and $B 2 M$ ) was subtracted from the expression value of the determined gene for each sample separately. Fig. 1 shows the transcriptomic levels of the genes of interest in all sample types [control mRNA from normal human rectum (Ctrl); adjacent rectal tissue of patients with pre-therapy (ART+) and adjacent rectal tissue of patients without pre-therapy (ART-)]. It can be clearly stated that the highest amplification was recorded for COL3A1, TIMP2 and COL1A1. Among MMPs, the highest 
Table II. Genes and size of products used in RT-qPCR assays acquired from Qiagen RT² qPCR Primer Assays database.

\begin{tabular}{|c|c|c|c|c|}
\hline Abbreviation & Full name & $\begin{array}{l}\text { Detected } \\
\text { transcripts }\end{array}$ & Band size & Reference position \\
\hline COL3A1 & Collagen, type III, $\alpha 1$ & $5,490 \mathrm{bp}$ & 95 & 4,287 (NM_000090) \\
\hline COL1A1 & Collagen, type I, $\alpha 1$ & $5,927 \mathrm{bp}$ & 75 & 3,760 (NM_000088) \\
\hline ACTB & Actin, $\beta$ & $1,852 \mathrm{bp}$ & 174 & 730 (NM_001101) \\
\hline MMP1 & Matrix metallopeptidase 1 (interstitial collagenase) & $2,081 \mathrm{bp}$ & 111 & 1,116(NM_002421) \\
\hline MMP2 & Matrix metallopeptidase 2 (gelatinase A) & $3,558 \mathrm{bp}$ & 69 & 1,594(NM_004530) \\
\hline MMP3 & Matrix metallopeptidase 3 (stromelysin 1, progelatinase) & $1,828 \mathrm{bp}$ & 70 & 1,173 (NM_002422) \\
\hline MMP8 & Matrix metallopeptidase 8 (neutrophil collagenase) & $3,056 \mathrm{bp}$ & 92 & 1,192(NM_002424) \\
\hline MMP9 & Matrix metallopeptidase 9 (gelatinase B) & $2,387 \mathrm{bp}$ & 36 & 2,085 (NM_004994) \\
\hline MMP10 & Matrix metallopeptidase 10 (stromelysin 2) & 1,777 bp & 120 & 1,224 (NM_002425) \\
\hline MMP13 & Matrix metallopeptidase 13 (collagenase 3 ) & $2,735 \mathrm{bp}$ & 61 & 1,380(NM_002427) \\
\hline TIMP1 & Tissue inhibitor of metallopeptidase 1 & $931 \mathrm{bp}$ & 91 & 243 (NM_003254) \\
\hline TIMP2 & Tissue inhibitor of metallopeptidase 2 & $3,670 \mathrm{bp}$ & 92 & 2,480 (NM_003255) \\
\hline TIMP4 & Tissue inhibitor of metallopeptidase 4 & $1,667 \mathrm{bp}$ & 128 & 1,316 (NM_003256) \\
\hline GAPDH & Glyceraldehyde-3-phosphate dehydrogenase & $1,421 \mathrm{bp}$ & 89 & 1,321 (NM_002046) \\
\hline $\mathrm{B} 2 \mathrm{M}$ & $\beta$-2-microglobulin & 987 bp & 114 & 357 (NM_004048) \\
\hline
\end{tabular}

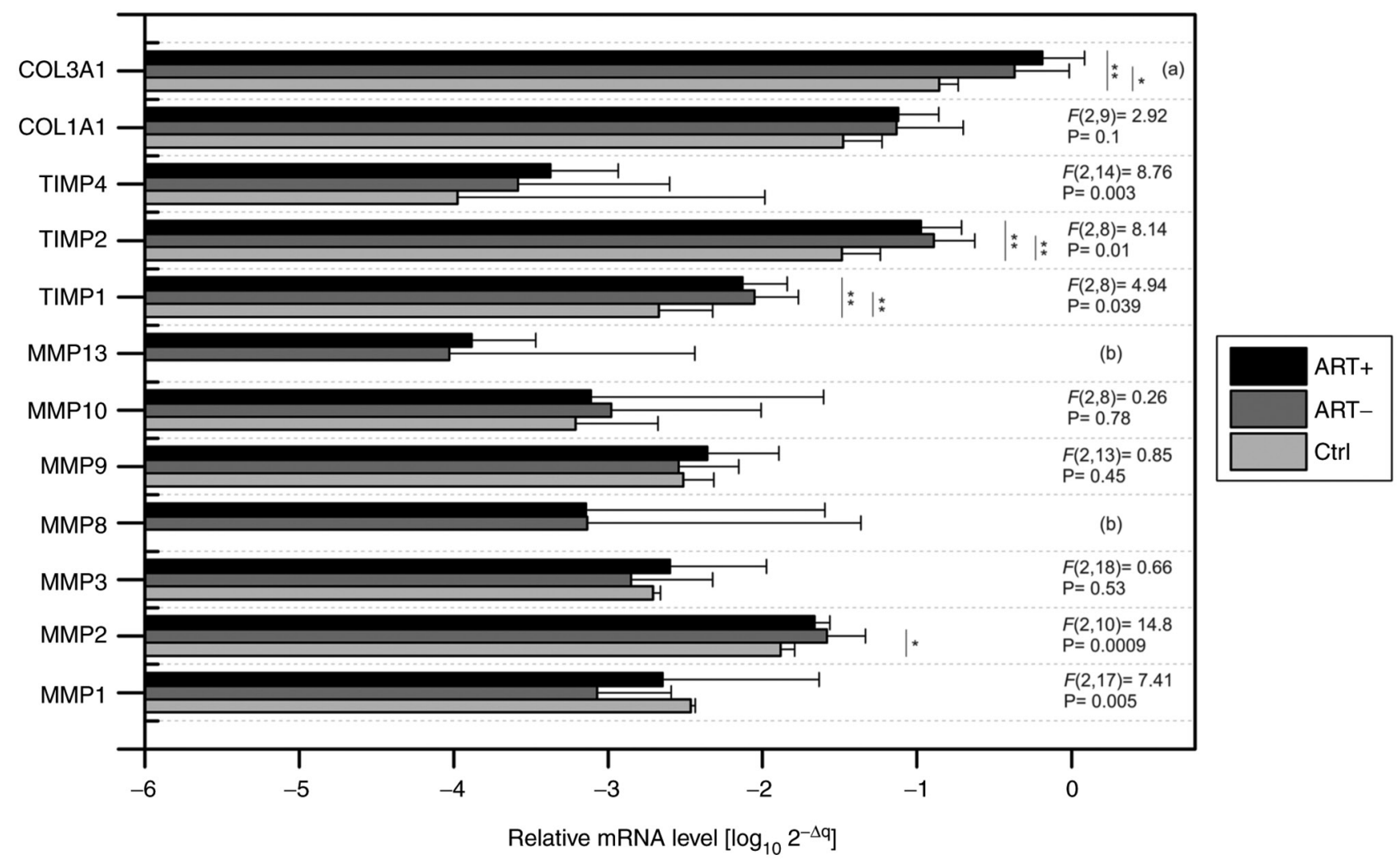

Figure 1. Relative logarithmic mRNA levels (MMPs, TIMPs and COLs) from Ctrl, the adjacent rectal tissue of patients with pre-therapy (ART+) and the adjacent rectal tissue of patients without pre-therapy (ART-). Factor score (F) was calculated between a three group of samples (n=33) using Welch's ANOVA and Tukey's HSD post-hoc test. All mRNA levels were normalised to the level of housekeeping genes: glyceraldehyde-3-phosphate dehydrogenase, $\beta$-actin and $\beta 2$-microglobulin. ${ }^{*} \mathrm{P}<0.05 ;{ }^{* *} \mathrm{P}<0.01$. (a) $\mathrm{F}(1,15)=22.24, \mathrm{P}<0.0001$. (b), no control; TIMPs, tissue inhibitors of metalloproteinases; COLs, collagens; Ctrl, healthy controls.

levels in $M M P 2$ were detected in both the control and patient samples. An absolute lack of amplification signal was accompanied by control of the human rectum for the MMPS and $M M P 13$ genes. In patient samples, amplification of MMP8 was detected in $65.5 \%$ of cases and MMP13 in $89 \%$ of cases. No statistical differences were observed when comparing gene levels between both patient groups. On the contrary, significant differences in the TIMP1, TIMP2, TIMP4 and COL3A1 genes 
Table III. Relationship between the expression of mRNAs and clinicobiochemical parameters in adjacent rectal tissues of patients with colorectal carcinoma.

Clinical and biochemical parameters (estimate; $P$-value)

\begin{tabular}{|c|c|c|c|c|c|c|c|c|}
\hline Gene symbol & Albumin & Age & BMI & Collagen & CRP & Therapy & Regression P-value & Adjusted $\mathrm{R}^{2}$ \\
\hline MMP1 & $\begin{array}{r}-11.66 \\
0.009\end{array}$ & & & & $\begin{array}{r}-0.688 \\
0.024\end{array}$ & $\begin{array}{l}9.58 \\
0.034\end{array}$ & 0.074 & 0.232 \\
\hline MMP2 & & $\begin{array}{l}0.015 \\
0.044\end{array}$ & & & & $\begin{array}{l}9.11 \\
0.043\end{array}$ & 0.044 & 0.14 \\
\hline MMP8 & $\begin{array}{c}-13.8 \\
0.011\end{array}$ & $\begin{array}{l}-0.09 \\
0.024\end{array}$ & $\begin{array}{l}0.288 \\
0.008\end{array}$ & $\begin{array}{c}-3.30 \\
0.001\end{array}$ & & & 0.005 & 0.74 \\
\hline MMP10 & $\begin{array}{r}-15.69 \\
0.003\end{array}$ & & & & $\begin{array}{c}-1.04 \\
0.024\end{array}$ & $\begin{array}{l}21.3 \\
0.002\end{array}$ & 0.05 & 0.38 \\
\hline COL1A1 & & & $\begin{array}{r}-0.144 \\
0.010\end{array}$ & $\begin{array}{l}0.92 \\
0.009\end{array}$ & & & 0.121 & 0.26 \\
\hline COL3A1 & $\begin{array}{l}2.34 \\
0.038\end{array}$ & & & $\begin{array}{l}1.47 \\
0.000\end{array}$ & & & $<0.000$ & 0.81 \\
\hline
\end{tabular}

BMI, body mass index; CRP, C-reactive protein.

were demonstrated when comparing patient samples with the control group (Fig. 1). Significantly increased MMP2 levels were also detected in patients without pre-therapy compared with controls $(-3.07$ vs. $-2.48, \mathrm{P}=0.025)$.

The comparison between gene levels and clinicobiochemical parameters of all patients is summarised in Table III, where only significant differences are shown.

It should be noted at the outset that none of the TIMP genes showed a relationship with the clinical parameters. $M M P 1$, MMP8 and MMP10 gene expression levels in all samples of patients were negatively related to albumin concentration. In contrast, a positive significant association of albumin vs. COL3A1 mRNA level was detected. Moreover, MMPI and $M M P 10$ were negative trends to $\mathrm{C}$-reactive protein values (Table III). The expression of MMP2 and COL $3 A 1$ correlated with increased age, while high levels of $M M P 8$ were typical for younger patients. In addition, it was demonstrated that the level of MMP8 increased with body mass index (BMI) value and decreased with the collagen concentration in the examined biopsies. The high expression of the COL1Al gene was significantly related to collagen concentration and was in overweight individuals (Table III). The weak effect of neoadjuvant therapy in association with $M M P 1, M M P 2$ and $M M P 10$ genes was observed.

Correlation between individual gene expression in ART samples. The present study investigated the correlations between individual levels of mRNA obtained from patient samples. The power of correlations (positive or negative) were categorised as low, medium and high according to their correlation coefficient and P-values (Fig. 2). The highest positive association of the $M M P 8$ gene was significantly related to the TIMPI gene $(0.78 ; \mathrm{P}=0.0001)$. The same strong effect was observed between TIMP1 and TIMP2 (0.7; $\mathrm{P}=0.00001)$. Among the significant positive correlations, the relationship between the two genes for collagen was considered. The remaining positive relationships are indicated by blue spots. A negative relationship (red spots) was detected between MMP1 and TIMP2 (-0.38; $\mathrm{P}=0.043)$, between MMP8 and both collagen genes (COL1A1: $-0.52 ; \mathrm{P}=0.020 ; C O L 3 A 1$ : $-0.57, \mathrm{P}=0.01)$ and between $M M P 9$ and $M M P 13(-0.42$; $\mathrm{P}=0.032)$.

Fold change in gene regulation. In this section, the present study focused on the regulatory changes of genes measured in the adjacent rectum tissue from carcinoma patients compared with control biopsies (RNAs from Human Adult Normal Rectum Tissue; Amsbio), where cancer status was not present. In addition, the patient samples were divided into two groups, with or without applied therapy. Table IV represents changes in fold regulation of individual genes. The data themselves were calculated as the difference of $\log _{10} 2^{-\Delta \mathrm{Cq}}$ between the groups of samples that are illustrated in Fig. 1. It was found that the present of therapy did not serve a significant role in the regulation of genes (Table IV). This was reflected in a parallel comparison of patient samples vs. the control samples. MMP2 (2.0 fold; $\mathrm{P}=0.025)$, TIMP1 (4.2; $\mathrm{P}=0.0022)$ and TIMP2 (3.9; $\mathrm{P}=0.0012)$ were significantly increased in patients without therapy (ART-), compared with the control. Similarly, the mRNA of COLIAI $(2.2 ; \mathrm{P}=0.22)$ and $C O L 3 A 1(3.1 ; \mathrm{P}=0.023)$ increased in the ART-group. TIMP1 showed the highest fold difference, while in the MMP1 gene higher downregulation was detected, but without statistical significance. The present study did not find fold-change differences in $M M P$ regulation between patient samples with therapy compared with the control. In contrast, fold regulation for TIMPs and COLs had a similar trend as in patients without therapy.

The present study confirmed the similar profile of fold regulation when comparing all patient samples versus the 


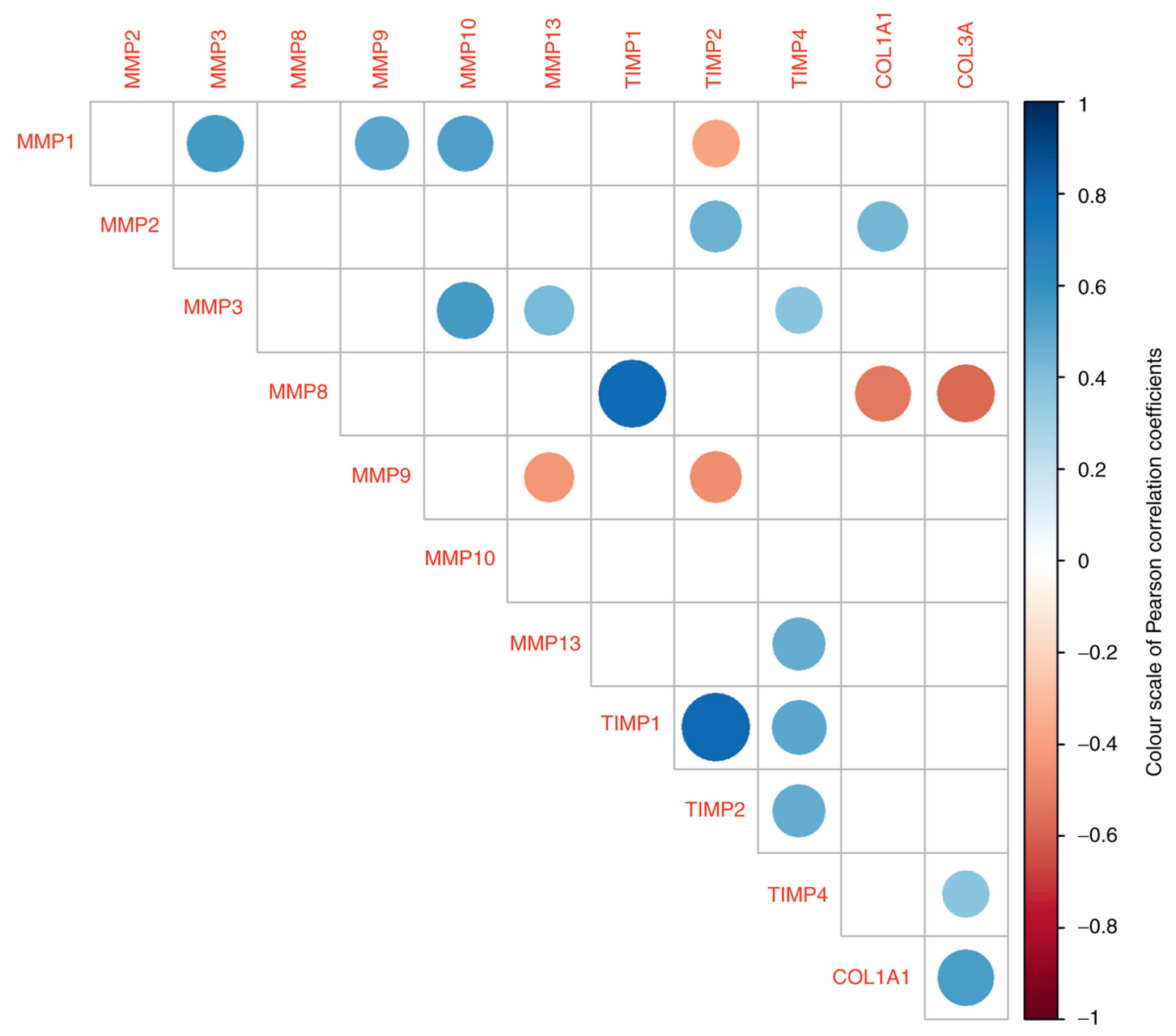

Figure 2. Correlation matrix of gene log levels for the pairs where the Pearson correlation is statistically significant. The blue colour of the dot represents a positive relationship between a pair of genes, while the red dot indicates a negative relationship. The intensity of the colour and the size of the dots indicate the strength of the correlation. TIMP, tissue inhibitor of metalloproteinases; COL, collagen.

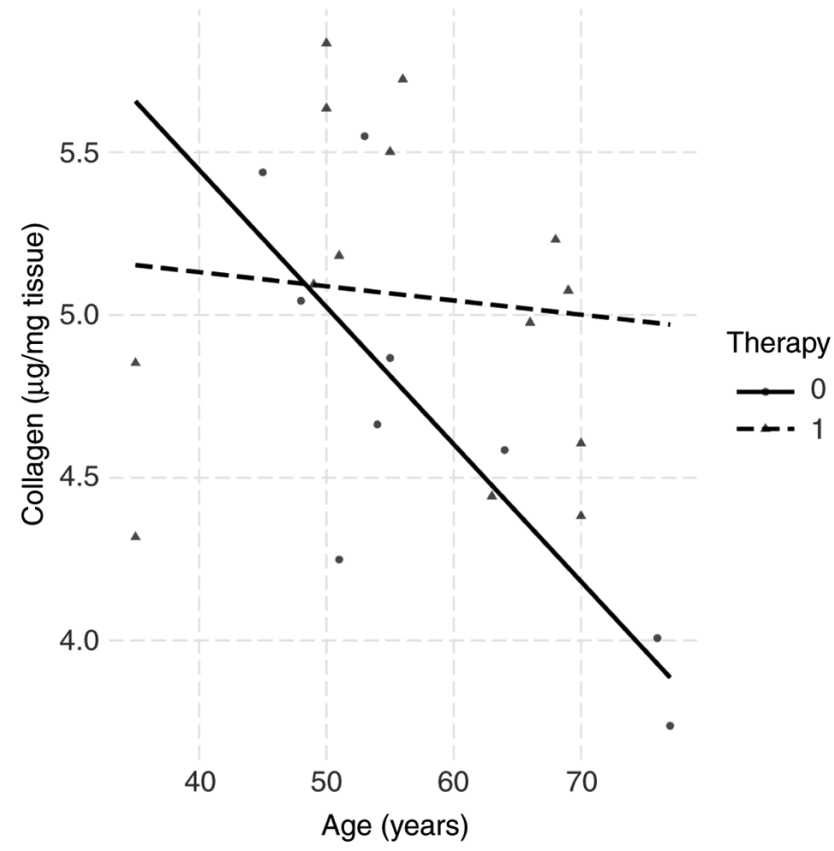

Figure 3. Interaction plot of collagen (log) vs. age for the two levels of factor therapy. The straight lines were obtained from the linear regression model. The regression slope of the full line was $-0.042(\mathrm{P}=0.009)$ and for the dashed line $-0.004(\mathrm{P}=0.052)$. control (ART/Ctrl; Table IV). As mentioned earlier, the therapy did not affect the change in gene regulation; although, the mRNA of $M M P I$ showed a non-significant upregulation in patients after therapy compared with patients without therapy (ART+/ART-).

Association between collagen concentration and clinicobiochemical parameters. The biopsies for collagen determination after storage at $-80^{\circ} \mathrm{C}$ weighed $75 \pm 5.2 \mathrm{mg}$ wet tissue. The relationships between the collagen concentrations of each patient and the clinicobiochemical parameters were then examined. The collagen amounts in the biopsies were unrelated to gender, BMI, proteins in plasma, leukocytes and plasma iron. In 24 biopsy specimens of rectal tissue, a decrease in collagen concentration with the patient's age was observed. Combined with the third parameter (neoadjuvant therapy), it was found that 13 patients who underwent preoperative therapy almost doubled their collagen content in rectal tissue (Fig. 3).

\section{Discussion}

It is apparent that the formation of CRC results in pathomolecular changes in the ECM of the colon tissue. Defective ECM 
Table IV. Comparison of fold regulation of gene expression changes in different rectal tissues.

\begin{tabular}{|c|c|c|c|c|}
\hline \multirow[b]{3}{*}{ Gene symbol } & \multicolumn{4}{|c|}{ Fold of regulation } \\
\hline & ART- & ART+ & ART & ART+ \\
\hline & Ctrl & Ctrl & Ctrl & ART- \\
\hline MMP1 & -4.04 & -1.52 & -2.48 & 2.65 \\
\hline MMP2 & $2.00^{\mathrm{a}}$ & 1.66 & 1.82 & -1.21 \\
\hline MMP3 & -1.39 & 1.29 & -1.04 & 1.79 \\
\hline MMP8 & ND & ND & $\mathrm{ND}$ & -1.02 \\
\hline MMP9 & -1.07 & 1.43 & 1.16 & 1.53 \\
\hline MMP10 & 1.70 & 1.26 & 1.46 & -1.35 \\
\hline MMP13 & ND & ND & ND & 1.40 \\
\hline TIMP1 & $4.21^{\mathrm{b}}$ & $3.51^{b}$ & $3.84^{b}$ & -1.20 \\
\hline TIMP2 & $3.94^{b}$ & $3.26^{\mathrm{b}}$ & $3.58^{b}$ & -1.21 \\
\hline TIMP4 & 2.47 & 3.98 & 3.13 & 1.61 \\
\hline COL1A1 & 2.22 & 2.27 & 2.25 & 1.02 \\
\hline COL3A1 & $3.08^{\mathrm{a}}$ & $4.64^{b}$ & $3.78^{\mathrm{a}}$ & 1.51 \\
\hline
\end{tabular}

The number representing a fold regulation relates to the reader in an appropriate ratio. Genes identified as deregulated $(\leq-2$ or $\geq 2)$ are presented in bold with a corresponding P-value $\left({ }^{\mathrm{a}}<0.05\right.$ or $\left.{ }^{\mathrm{b}}<0.01\right)$. Ctrl, human normal rectal tissue-control sample; ART-, adjacent rectal tissue without therapy; ART+, adjacent rectal tissue with therapy; ART, all adjacent rectal tissues; ND, not determined.

remodelling is associated with the accumulation of inflammatory cells, the presence of apoptotic cells, neovascularisation, hypoxia and loss of elastic fibres $(29,30)$. Previous studies based on proteomic or transcriptomic analyses point to specific molecules that are dysregulated in the progress of colorectal carcinoma $(31,32)$. Collagen is a key factor among ECM adhesive components that regulate tumorigenesis and stages of cancer $(29,33)$. In general, it is known that the collagen content in rectal tissue is at a low level compared with other tissues of the digestive tract (34). Moreover, the decrease in collagen content is exacerbated by age, which was also confirmed in the present study. By contrast, patients who underwent standard neoadjuvant therapy showed increased concentrations of collagen in the ART. Previous studies have shown an increase in collagen in tumour tissues compared with normal tissue $(35,36)$.

From the monitored clinicobiochemical parameters, a positive relationship between collagen content and body mass index and a negative relationship to age, respectively, was observed. An increase in interstitial collagen content, the main hallmark of fibrosis, is correlated with an increase in BMI in the ECM of adipose stromal cells from breast cancer patients (37).

It was notable that by applying neoadjuvant therapy before surgical removal of the tumour a positive trend in the content of collagen in the rectal tissue after resection was attained. Impaired content or the synthesis of collagen can cause anastomotic leakage after tumour resection (34). It was hypothesized that the composition of collagens in normal tissue may be most affected by the presence and aggression of a CRC.
Collagen-rich stroma in aggressive colon tumours induces mesenchymal gene expression and tumour cell invasion based on different biochemical processes (38). Liang et al (19) observed collagen remodelling in CRC, demonstrating that the collagen fibres in normal intestinal mucosa were thin, wavy and dispersed. However, in the CRC tissues, the collagen fibres were more linearised and denser than in normal samples.

In CRC, special proteolytic enzymes (MMPs and TIMPs) serve critical roles in the metabolism of collagen. It was decided to draw attention to the relationship between individual mRNAs (COL vs. MMP or TIMP) in adjacent normal tissue of patients with CRC. In the present study, the main methodological difference compared with other publications was the use of control RNA for transcriptomic analysis. Several previous studies have compared MMP or TIMP gene expression levels between colon carcinoma tissue and adjacent normal mucosa $(19,34,39)$. Yamada et al (39) showed that the expressions of $M M P 9, M M P 13$ and TIMP1 were higher in cancer tissue than in the adjacent normal biopsies of 202 patients.

The present study detected the absolute absence of the MMP8 and MMP13 genes in normal human rectal tissue, which was almost identical to the data from Buch et al (34). That study demonstrated that $M M P 8$ is not detected in any part of the rectum tissue and MMP13 was only detected in 9 of 34 analysed samples. By contrast, the present study showed the highest mRNA levels for COL1A1, COL3A1, TIMP2 and $M M P 2$ in control or patient samples.

In addition, there is still a lack of information about the relationship between the mRNA of collagen, MMPs and tissue inhibitors of MMPs. It was thought-provoking to monitor the correlation between log-transformed gene expressions in the ART of patients with CRC. In the correlation analysis, it is necessary to emphasise the positive relationship between collagen mRNAs, COLIAI and COL3A1. Collagenase (MMP8 protein) is a protein that has functions in the degradation of type I, II and III collagens. This protein is encoded by the MMP8 gene (40), which was the only one to show a negatively significant relationship with genes encoding collagens, both COL1A1 and COL3A1. Therefore, it was hypothesized that $M M P 8$ was a key gene in the degradation of collagen due to the fact that MMP8 was detected in only $65.5 \%$ of patient cases. In addition, a negative correlation with TIMP1 may be another regulatory effect on the said gene. Although the increase in serum MMP8 and TIMP2 levels is related to the presence of an inflammatory process $(41,42)$, the present study was unable to correlate these markers with $\mathrm{C}$-reactive protein, which is another sign of inflammation.

The mainstay of the present study was the results regarding changes in gene regulation between groups of samples. Based on the changes in fold regulation, it can be concluded that mRNA levels of TIMPs were significantly higher in ARTs compared with the control. A similar result was obtained for genes encoding collagens. It was therefore considered that the regulatory effect on the synthesis of collagen will be affected by TIMPs rather than MMPs. The present study hypothesized that higher levels of TIMPs in the adjacent tumour tissue had an inhibitory effect on $M M P S$ and thus promoted collagen production. Several studies in CRC confirm the role of TIMPS 
as inhibitors of MMPs. In particular, TIMPI inhibits most $M M P s$ and its expression correlates with poor survival of CRC patients (43). Park et al (44) showed the inhibition of $M M P 2$ and $M M P 9$ by TIMP2 with CRC invasion and worse prognosis. Finally, TIMP4 suppresses MMP2 and its expression in rectal cancer correlates with longer patient survival (45).

Although there was a small number of samples, the present study provides unique information on the transcriptomic relationship between the mRNA of collagens, MMPs and tissue inhibitors of MMPs. Unlike other studies, it did not compare levels of genes in normal tissue of the same patient with CRC, which is a limitation of the present study.

The main outcome of the present study was the determination of higher levels of COLIA1,COL3A1 and selected TIMPs in the ART of CRC patients compared with the normal control group. This finding suggested that TIMPs served an important role in the regulation of MMPs and, hence, the remodelling of collagen in the ECM.

MMP8 may serve an important role in collagen metabolism since it was not amplified in the control samples compared with the tissue adjacent to the tumour. In addition, an increase in collagen concentration after the application of preoperative neoadjuvant therapy in patients with CRC was demonstrated.

The present study confirmed the influence of CRC on the expression of TIMPs and MMPs in the vicinity of the tumour tissue, but, at the same time, it is necessary to point out other factors associated with the process of tumorigenesis.

\section{Acknowledgements}

Not applicable.

\section{Funding}

This work was supported by the Ministry of Health of the Slovak Republic (grant nos. 2018/16-UKMT-12 and 2019/64UKMT-3) and by the Slovak Research and Development Agency under the contract no. APVV-18-0088.

\section{Availability of data and materials}

The datasets used and analysed during the current study are available from the corresponding author on reasonable request.

\section{Authors' contributions}

KD conceived and designed the experiments. KD and ZM performed the experiments and contributed to the acquisition of the data. AS and JV contributed to the acquisition of the clinical data. AS, MA and JV made substantial contribution to the collection of tissue samples. MG and $\mathrm{JH}$ were responsible for statistical analysis and data correlation. KD and $\mathrm{JH}$ wrote the manuscript. AF made substantial contributions to conception and design. $\mathrm{JH}$, as the corresponding author, was responsible for final correction. $\mathrm{KD}$ and $\mathrm{JH}$ confirm the authenticity of all the raw data. All authors have examined the manuscript. All authors read and approved the manuscript and agree to be accountable for all aspects of the research in ensuring that the accuracy or integrity of any part of the work are appropriately investigated and resolved.

\section{Ethics approval and consent to participate}

The experiment was approved by the Jessenius Faculty of Medicine CU in Martin and The Faculty Hospital in Zilina, Slovakia. This study was approved by the Ethics Committee of the Jessenius Faculty of Medicine CU in Martin (approval no. 1/2019) and written informed consent was obtained from all patients. The present study was performed in accordance with the Declaration of Helsinki.

\section{Patient consent for publication}

Not applicable.

\section{Competing interests}

The authors declare that they have no competing interests.

\section{References}

1. Siegel RL, Miller KD and Jemal A: Cancer statistics. CA Cancer J Clin 65: 5-29, 2015.

2. Sung H, Ferlay J, Siegel RL, Laversanne M, Soerjomataram I, Jemal A and Bray F: Global cancer statistics 2020: GLOBOCAN estimates of incidence and mortality worldwide for 36 cancers in 185 countries. CA Cancer J Clin 71: 209-249, 2021.

3. Siegel RL, Miller KD, Fedewa SA, Ahnen DJ, Meester RGS, Barzi A and Jemal A: Colorectal cancer statistics, 2017. CA Cancer J Clin 67: 177-193, 2017.

4. Kverneng Hultberg D, Svensson J, Jutesten H, Rutegård J, Matthiessen P, Lydrup ML and Rutegård M: The impact of anastomotic leakage on long-term function after anterior resection for rectal cancer. Dis Colon Rectum 63: 619-628, 2020.

5. Smith JD, Butte JM, Weiser MR, D'Angelica MI, Paty PB, Temple LK, Guillem JG, Jarnagin WR and Nash GM: Anastomotic leak following low anterior resection in stage IV rectal cancer is associated with poor survival. Ann Surg Oncol 20: 2641-2646, 2013.

6. Hain E, Maggiori L, Manceau G, Mongin C, Prost À la Denise J and Panis Y: Oncological impact of anastomotic leakage after laparoscopic mesorectal excision. Br J Surg 104: 288-295, 2017.

7. Karim A, Cubas V, Zaman S, Khan S, Patel H and Waterland P: Anastomotic leak and cancer-specific outcomes after curative rectal cancer surgery: A systematic review and meta-analysis. Tech Coloproctol 24: 513-525, 2020.

8. Zhou X, Wang B, Li F, Wang J and Fu W: Risk factors associated with nonclosure of defunctioning stomas after sphincter-preserving low anterior resection of rectal cancer: A meta-analysis. Dis Colon Rectum 60: 544-554, 2017.

9. Ashraf SQ, Burns EM, Jani A, Altman S, Young JD, Cunningham C, Faiz O and Mortensen NJ: The economic impact of anastomotic leakage after anterior resections in English NHS hospitals: Are we adequately remunerating them? Colorectal Dis 15: e190-e198, 2013.

10. Hammond J, Lim S, Wan Y, Gao X and Patkar A: The burden of gastrointestinal anastomotic leaks: An evaluation of clinical and economic outcomes. J Gastrointest Surg 18: 1176-1185, 2014.

11. Meyer J, Naiken S, Christou N, Liot E, Toso C, Buchs NC and Ris F: Reducing anastomotic leak in colorectal surgery: The old dogmas and the new challenges. World J Gastroenterol 25: 5017-5025, 2019.

12. Kawada K and Sakai Y: Preoperative, intraoperative and postoperative risk factors for anastomotic leakage after laparoscopic low anterior resection with double stapling technique anastomosis. World J Gastroenterol 22: 5718-5727, 2016.

13. Qu H, Liu Y and Bi DS: Clinical risk factors for anastomotic leakage after laparoscopic anterior resection for rectal cancer: A systematic review and meta-analysis. Surg Endosc 29: 3608-3617, 2015.

14. Rink AD, Kienle P, Aigner F and Ulrich A: How to reduce anastomotic leakage in colorectal surgery-report from German expert meeting. Langenbecks Arch Surg 405: 223-232, 2020.

15. Xu R, Won JY, Kim CH, Kim DE and Yim H: Roles of the phosphorylation of transcriptional factors in epithelial-mesenchymal transition. J Oncol 2019: 5810465, 2019. 
16. Ricard-Blum S: The collagen family. Cold Spring Harb Perspect Biol 3: a004978, 2011.

17. Ohlund D, Lundin C, Ardnor B, Oman M, Naredi P and Sund M: Type IV collagen is a tumour stroma-derived biomarker for pancreas cancer. Br J Cancer 101: 91-97, 2009.

18. Qiu S, Deng L, Liao X, Nie L, Qi F, Jin K, Tu X, Zheng X, Li J, Liu L, et al: Tumor-associated macrophages promote bladder tumor growth through PI3K/AKT signal induced by collagen. Cancer Sci 110: 2110-2118, 2019.

19. Liang Y, Lv Z, Huang G, Qin J, Li H, Nong F and Wen B: Prognostic significance of abnormal matrix collagen remodeling in colorectal cancer based on histologic and bioinformatics analysis. Oncol Rep 44: 1671-1685, 2020.

20. Xu S, Xu H, Wang W, Li S, Li H, Li T, Zhang W, Yu X and Liu L: The role of collagen in cancer: From bench to bedside. J Trans Med 17: 309, 2019.

21. Libra M, Scalisi A, Vella N, Clementi S, Sorio R, Stivala F, Spandidos DA and Mazzarino C: Uterine cervical carcinoma: Role of matrix metalloproteinases (review). Int J Oncol 34: 897-903, 2009

22. Egeblad M and Werb Z: New functions for the matrix metalloproteinases in cancer progression. Nat Rev Cancer 2: 161-174, 2002.

23. Murphy G: Tissue inhibitors of metalloproteinases. Genome Biol 12: 233, 2011

24. Medina $\mathrm{C}$ and Radomski MW: Role of matrix metalloproteinases in intestinal inflammation. J Pharmacol Exp Ther 318: 933-938, 2006.

25. DI Carlo A: Matrix metalloproteinase- 2 and -9 and tissue inhibitor of metalloproteinase- 1 and -2 in sera and urine of patients with renal carcinoma. Oncol Lett 7: 621-626, 2014.

26. Herszényi L, Hritz I, Lakatos G, Varga MZ and Tulassay Z: The behavior of matrix metalloproteinases and their inhibitors in colorectal cancer. Int J Mol Sci 13: 13240-13263, 2012.

27. Knight CD and Griffen FD: An improved technique for low anterior resection of the rectum using the EEA stapler. Surgery 88 710-714, 1980.

28. Schmittgen TD and Livak KJ: Analyzing real-time PCR data by the comparative C(T) method. Nat Protoc 3: 1101-1108, 2008.

29. LeCC,Bennasroune A,Langlois B,Salesse S, Boulagnon-RombiC, Morjani H, Dedieu S and Appert-Collin A: Functional interplay between collagen network and cell behavior within tumor microenvironment in colorectal cancer. Front Oncol 10: 527, 2020.

30. Yuzhalin AE, Lim SY, Kutikhin AG and Gordon-Weeks AN: Dynamic matrisome: ECM remodeling factors licensing cancer progression and metastasis. Biochim Biophys Acta Rev Cancer 1870: 207-228, 2018

31. Yuzhalin AE, Urbonas T, Silva MA, Muschel RJ and Gordon-Weeks AN: A core matrisome gene signature predicts cancer outcome. Br J Cancer 118: 435-440, 2018

32. Naba A, Clauser KR, Whittaker CA, Carr SA, Tanabe KK and Hynes RO: Extracellular matrix signatures of human primary metastatic colon cancers and their metastases to liver. BMC Cancer 14: 518, 2014.

33. Skovbjerg H, Anthonsen D, Lothe IM, Tveit KM, Kure EH and Vogel LK: Collagen mRNA levels changes during colorectal cancer carcinogenesis. BMC Cancer 9: 136, 2009.
34. Buch AS, Schjerling P, Kjaer M, Jorgensen LN, Krarup PM and Ågren MS: Impaired collagen synthesis in the rectum may be a molecular target in anastomotic leakage prophylaxis. Wound Repair Regen 25: 532-535, 2017.

35. Zou X, Feng B, Dong T, Yan G, Tan B, Shen H, Huang A, Zhang $\mathrm{X}$, Zhang $\mathrm{M}$, Yang $\mathrm{P}$, et al: Up-regulation of type I collagen during tumorigenesis of colorectal cancer revealed by quantitative proteomic analysis. J Proteomics 94: 473-485, 2013.

36. Yang Q, Feng M, Ma X, Li H and Xie W: Gene expression profile comparison between colorectal cancer and adjacent normal tissues. Oncol Lett 14: 6071-6078, 2017.

37. Springer NL, Iyengar NM, Bareja R, Verma A, Jochelson MS, Giri DD, Zhou XK, Elemento O, Dannenberg AJ and Fischbach C: Obesity-Associated extracellular matrix remodeling promotes a macrophage phenotype similar to tumor-associated macrophages. Am J Pathol 189: 2019-2035, 2019.

38. Vellinga TT, den Uil S, Rinkes IH, Marvin D, Ponsioen B, Alvarez-Varela A, Fatrai S, Scheele C, Zwijnenburg DA, Snippert $\mathrm{H}$, et al: Collagen-rich stroma in aggressive colon tumors induces mesenchymal gene expression and tumor cell invasion. Oncogene 35: 5263-5271, 2016.

39. Yamada T, Oshima T, Yoshihara K, Tamura S, Kanazawa A, Inagaki D, Yamamoto N, Sato T, Fujii S, Numata K, et al: Overexpression of MMP-13 gene in colorectal cancer with liver metastasis. Anticancer Res 30: 2693-2699, 2010.

40. Hasty KA, Pourmotabbed TF, Goldberg GI, Thompson JP, Spinella DG, Stevens RM and Mainardi CL: Human neutrophil collagenase. A distinct gene product with homology to other matrix metalloproteinases. J Biol Chem 265: 11421-11424, 1990.

41. Böckelman C, Beilmann-Lehtonen I, Kaprio T, Koskensalo S, Tervahartiala $\mathrm{T}$, Mustonen $\mathrm{H}$, Stenman UH, Sorsa $\mathrm{T}$ and Haglund C: Serum MMP-8 and TIMP-1 predict prognosis in colorectal cancer. BMC Cancer 18: 679, 2018.

42. Schmalz G, Davarpanah I, Jäger J, Mausberg RF, Krohn-Grimberghe B, Schmidt J, Haak R, Sack U and Ziebolz D: MMP-8 and TIMP-1 are associated to periodontal inflammation in patients with rheumatoid arthritis under methotrexate immunosuppression-First results of a cross-sectional study. J Microbiol Immunol Infect 52: 386-394, 2019.

43. Lee JH, Choi JW and Kim YS: Plasma or serum TIMP-1 is a predictor of survival outcomes in colorectal cancer: A meta-analysis. J Gastrointestin Liver Dis 20: 287-291, 2011.

44. Park KS, Kim SJ, Kim KH and Kim JC: Clinical characteristics of TIMP2, MMP2 and MMP9 gene polymorphisms in colorectal cancer. J Gastroenterol Hepatol 26: 391-397, 2011.

45. Hilska M, Roberts PJ, Collan YU, Laine VJ, Kössi J, Hirsimäki P, Rahkonen $\mathrm{O}$ and Laato M: Prognostic significance of matrix metalloproteinases- $1,-2,-7$ and -13 and tissue inhibitors of metalloproteinases-1, $-2,-3$ and -4 in colorectal cancer. Int J Cancer 121: 714-723, 2007.

This work is licensed under a Creative Commons Attribution-NonCommercial-NoDerivatives 4.0 International (CC BY-NC-ND 4.0) License. 